\title{
Infección por SARS-CoV-2 en Niños
}

\section{SARS-CoV-2 Infection in Children}

(iD) Luis Miguel Franchi Prato $₫$

Universidad Peruana de Ciencias Aplicadas. Lima, Perú

\begin{tabular}{llll}
\hline Recibido: $26 / 08 / 2020$ & Revisado: 01/09/2020 & Aceptado: 02/09/2020 & Publicado: 25/10/2020 \\
\hline
\end{tabular}

\section{RESUMEN}

A fines de 2019 se inicia en Asia una pandemia de Enfermedad por Coronavirus 19 (COVID-19). Esta enfermedad llega al Perú en marzo de 2020 afectando principalmente a adultos pero también a niños. La información disponible parece indicar que los niños son tan susceptibles como los adultos de contraer esta enfermedad, generalmente de otro miembro de la familia, siendo asintomáticos en la mayoría de los casos, pero sin perder la capacidad de contagiar el virus a otras personas. Los adultos, por otro lado, adquieren la enfermedad en la comunidad y presentan sintomatología más severa. En este artículo revisamos las características epidemiológicas, clínicas y de tratamiento de esta enfermedad en pacientes menores de 18 años.

Palabras clave: COVID_19, epidemiología, clínica, tratamiento, prevención.

\begin{abstract}
At the end of 2019 a Coronavirus Disease 19 (COVID-19) pandemic starts in Asia. This disease arrives in Peru in March 202 affecting mainly adults but also children. The current available information indicates that children are as susceptible as adults to get this disease, generally from another household member, being asymptomatic in most cases but maintaining the capability of transmitting the virus to other persons. Adults, on the other side, acquire the disease from the community and have more severe symptoms. In this article we review the epidemiological and clinical characteristics of the disease and its treatment in patients under 18 years of age.
\end{abstract}

Keywords: COVID_19, epidemiology, clinical, treatment, prevention. 


\section{INTRODUCCIÓN}

La familia Coronavirus está constituida por virus RNA zoonóticos que infectan diferentes especies de animales, produciendo diversas enfermedades en ellos. También infectan a los seres humanos generando sintomatología respiratoria como rinorrea, tos, fiebre, inflamación faríngea y laríngea y broncoespasmo. Adicionalmente pueden afectar el sistema digestivo produciendo diarrea. En casos serios pueden llegar a producir distrés respiratorio agudo severo coagulopatías y la muerte especialmente en personas con enfermedades crónicas coexistentes (Zimmermann, 2020). E SARS-CoV-2 pertenece al grupo de los Betacoronavirus e hizo su aparición en la provincia de Wuhan en China en diciembre de 2019 a través de la infección en humanos por consumo de carne de murciélago. Desde entonces se ha diseminado por el mundo llegando al Perú en marzo de 2020. El término COVID-19 se usa para referirse a la enfermedad causada por el SARS-CoV-2.

Siendo la COVID-19 una enfermedad que afecta primordialmente a adultos y en la que la gran mayoría de pacientes menores de 18 años son asintomáticos (Ludvigsson, 2020) la información sobre la evolución de ella en este grupo etario es limitada. Más aún sientendemos que solo han pasado 8 meses desde su aparición. A continuación, revisaremos las características epidemiológicas, clínicas y de tratamiento en niños y adolescentes incorporando la data peruana disponible.

\section{DESARROLLO Epidemiología}

Los Coronavirus se encuentran como agentes causales en el 4 a $7 \%$ de las enfermedades respiratorias en niños (Cabeca, 2013 y Ludvigsson, 2020) muchas veces coincidiendo con otros virus como el sincicial respiratorio, influenza y rinovirus. En la gran mayoría de casos esos pacientes presentan sintomatología leve siendo más severa en aquellos niños con enfermedades debilitantes.

En el caso específico del SARS-CoV-2, las series reportadas en China estiman que aproximadamente el $2 \%$ de los casos reportados en este país fueron pacientes menores de 18 años y datos similares se reportan en series estadounidenses (Zunyou, 2020).

En el Perú, la incidencia estimada de casos en menores de 18 años, definidos como la presencia de síntomas consistentes con la enfermedad más una prueba diagnóstica positiva, es de $5 \%$ según data del Ministerio de Salud (tabla 1). lo cual es más del doble de la incidencia global reportada. Esto debido principalmente a un incremento en el contagio intradomiciliario donde los adultos traen el virus de la comunidad.

Tabla 1. Casos positivos de COVID-19 según grupos etarios

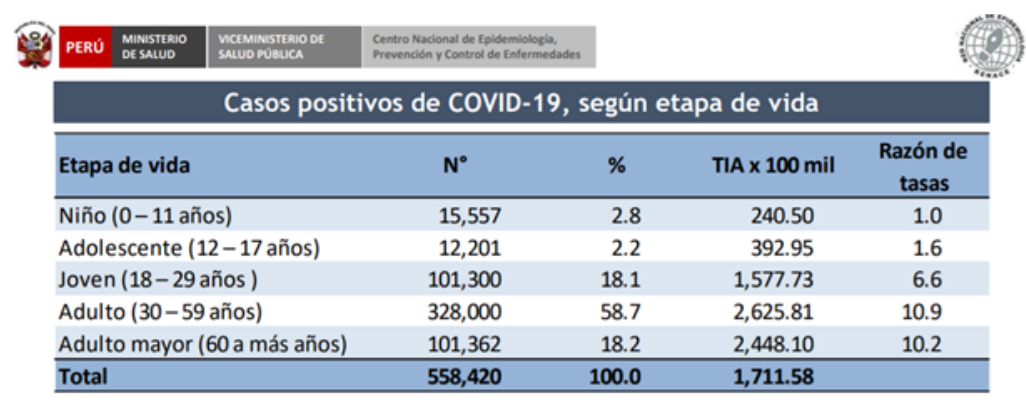

Fuente: Centro Nacional de Epidemiología, Prevención y Control de Enfermedades - MINSA 


\section{Transmisión}

El SARS-CoV-2 se transmite de personas enfermas $\mathrm{O}$ asintomáticas a través de partículas suspendidas en el aire originadas por toser, estornudar, gritar, etc. También es posible la transmisión por micropartículas en aerosol. Estas partículas y micropartículas contienen una carga viral que se incrementa en proporción a la severidad de la enfermedad. Al depositarse en la mucosa oral, nasal o conjuntival el virus se une a las células epiteliales mediante la proteína $S$ de su envoltura lipoprotéica, con la cual se adhiere al receptor ACE-2 que está presente en las membranas apicales de las células de la mucosa (Dohchak et al,. 2020). Una vez dentro de la célula, libera el ARN que se replica y forma nuevas partículas virales que salen para infectar nuevas células (Perez et al., 2020) (Figura 1).

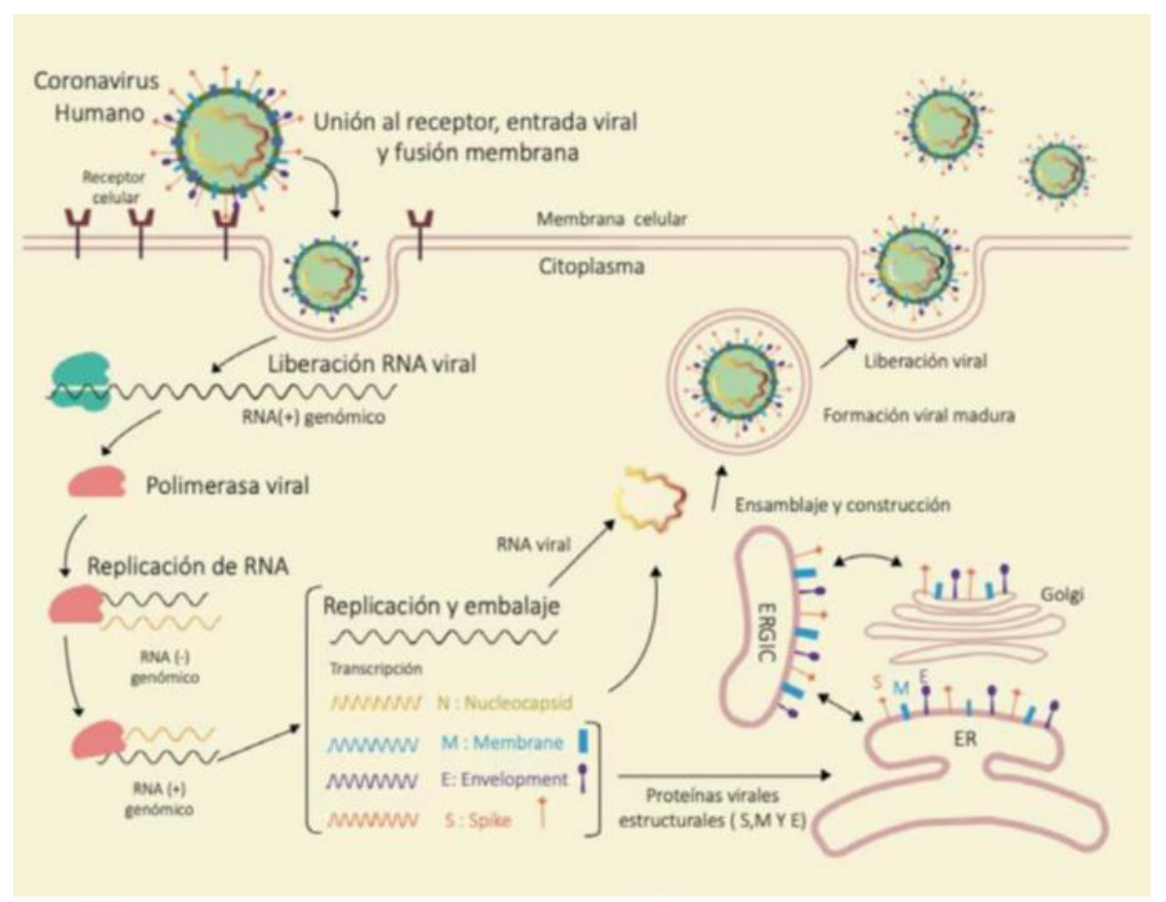

Figura 1. Infección celular por el SARS-CoV-2. Luego de adherirse al receptor ACE2 el virus ingresa a la célula y libera la cadena de RNA la cuál es replicada por acción de una polimerasa viral. En paralelo se codifican, también, proteínas estructurales que formarán nuevas partículas virales y serán liberadas. Tomado de Perez Gema et al.,202

Como mencionamos anteriormente, la transmisión del SARS-CoV-2 a niños ocurre principalmente en el hogar a través de adultos que traen al virus de la comunidad. En el caso de adolescentes el contagio es similar a los adultos al exponerse comunitariamente. En el caso de los recién nacidos, la transmisión también es por contacto con adultos infectados ya no hay evidencia, hasta ahora, que apoye la infección transplacentaria (Cabero-Perez et al., 2020).

Por otro lado, los niños son capaces de infectar a los adultos a pesar de ser asintomáticos. Más aún, existen reportes 
indicando que los niños pueden tener una carga viral bastante elevada a pesar de tener pocos o ningún síntoma, llegando a ser similar a la de los pacientes adultos con enfermedad severa (Yonker et al., 2020). Esto resalta la importancia de los niños como elementos transmisores de la infección dentro de la familia.

Las partículas o micropartículas pueden depositarse en diferentes superficies donde el virus puede permanecer viable por tiempo variable. Al tocar los niños estas superficies y luego la cara con la mano llevan el virus a las mucosas y se infectan.

Es debido a estos mecanismos de transmisión que las medidas preventivas para controlar la expansión de la infección deben incluir el uso obligatorio de mascarillas, el distanciamiento entre personas y el lavado o desinfección de manos frecuente.

\section{Clínica}

La infección por SARS-CoV-2 pasa por varios fases: el periodo de incubación, que en promedio dura 5 a 7 días pudiendo ser de hasta 14; la fase infecciosa en la que el virus desencadena síntomas similares a una gripe con fiebre, rinorrea, malestar general, dolores musculares, tos y perdida del olfato y gusto; una fase de neumonía viral y una fase inflamatoria en la que una reacción exagerada del sistema inmune del paciente produce daño multisistémico, principalmente respiratorio que puede llevar a los pacientes a necesitar cuidados intensivos y, eventualmente, fallecer (Berlin, 2020).

La sintomatología de la COVID-19 en niños y adolescentes tiende a ser bastante más leve que en adultos, siendo la mayoría asintomáticos.

Las primeras series pediátricas reportadas refieren fiebre y tos como los síntomas más prevalentes seguidos de diarrea y rinorrea (Yonker et al., 2020 y Xia, et al., 2020). Adicionalmente, los síntomas gas- trointestinales son más prevalentes en niños.

Si bien la sintomatología es más leve en niños, en algunos casos puede presentarse un síndrome inflamatorio generalizado denominado MIS-C (Multisystem Inflammatory Síndrome in Children), bastante similar al Síndrome de Kawasaki, que aparece varias semanas después de exponerse al virus y que se define como fiebre por más de 24 horas, evidencia de inflamación de dos o más órganos, rash cutáneo y una prueba positiva de infección por SAR-CoV-2 (Yonker et al., 2020).

Los hallazgos de laboratorio son similares a los de los adultos, con disminución de leucocitos, trombocitopenia y elevación de marcadores inflamatorios como la Proteína C Reactiva, Velocidad de Sedimentación, Enzimas Hepáticas, Procalcitonina y Deshidrogenasa Láctica.

Las radiografías de tórax y tomografías Computarizadas muestran infiltrados bilaterales en parches, opacidades en vidrio esmerilado y consolidaciones

Existen varias posibles razones por las que la infección por el SARS-CoV-2 en los niños es más leve. La expresión de ACCE-2 en la nasofaringe es menor en este grupo etario y aumenta con la edad, esto disminuiría la capacidad del virus para ingresar a las células de la mucosa respiratoria. Exposición frecuente a otros Coronavirus podrían generar inmunidad cruzada que puede controlar la infección. El recibir vacunas con cierta frecuencia en la niñez puede mantener al sistema inmune más activo que en los adultos mejorando su capacidad de respuesta frente a la infección (Dohchak et al., 2020).

La mortalidad por COVID-19 en niños también es bastante menor que en los adultos, siendo los niños menores de 1 año y aquellos con co-morbilidades los que tienen mayor riesgo de tener enfermedad seria y fallecer. 
El diagnóstico de la COVID-19 en niños se hace en base al antecedente de exposición a un adulto infectado, la sintomatología y una prueba diagnóstica positiva. Siendo la mayoría de los casos asintomáticos o muy leves es necesario un alto nivel de sospecha para indicar estas pruebas y confirmar el caso.

La principal prueba diagnóstica es la detección de la secuencia genética del virus mediante la Reacción de Cadena de Polimerasa en Tiempo Real (RT-PCR) o prueba molecular como también se le conoce. Esta puede ser positiva desde unos días antes de la aparición de los síntomas hasta aproximadamente diez días después de estos en promedio. Adicionalmente se puede determinar la presencia de anticuerpos contra el virus usando las llamadas pruebas rápidas que emplean técnicas de ELISA - Inmunocromatografía para detectar inmunoglobulinas $A, M$ y $G$ en sangre total o suero (pruebas rápidas o serológicas) que se elevan secuencialmente dos semanas después de la aparición de los síntomas en promedio (PAHO, 2020) (Figura 2).

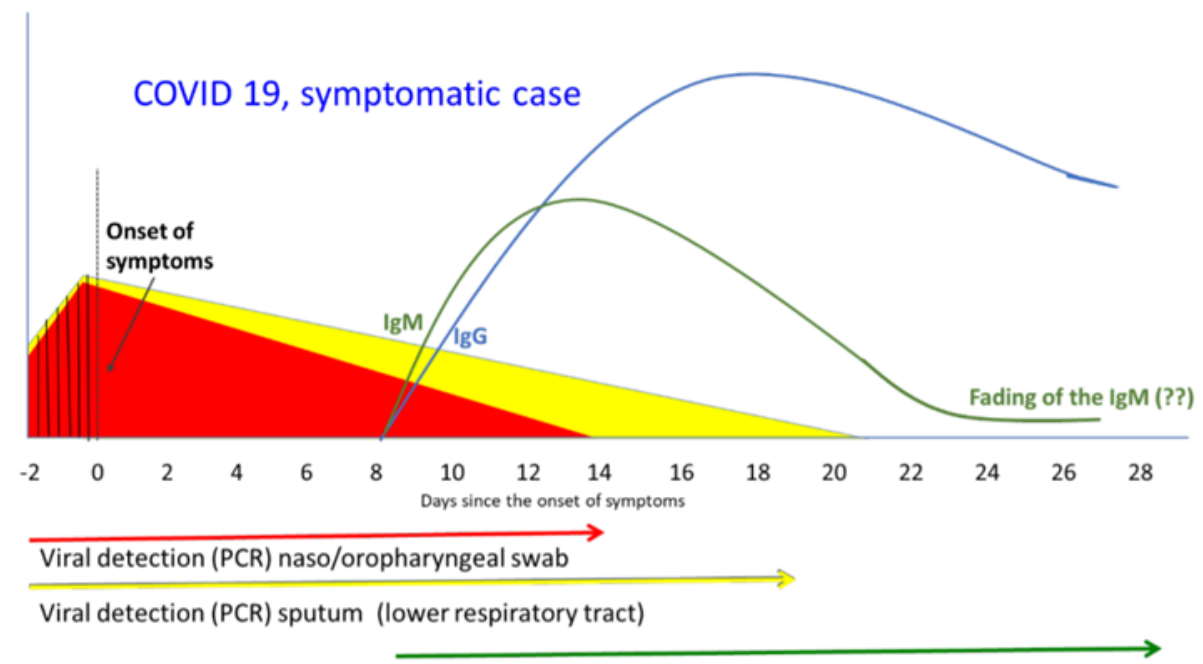

Antibody detection ( $\operatorname{lgM} / \operatorname{lgG}$ ) in serum sample

Figura 2. Secuencia de positividad de las diferentes pruebas diagnósticas para la COVID-19. Tomado de www.paho.org/coronavirus

\section{Tratamiento}

Hasta la fecha no existe un tratamiento específico y claramente definido para la COVID-19. Sin embargo, el conocimiento adquirido estudiando otras formas de infección por Coronavirus (MERS-CoV y SARS-CoV) ha permitido definir una serie de opciones que están en diferentes fases de investigación clínica para determinar si alguna de las diferentes alternativas investigadas ofrece resultados positivos. Todos esto estudios se están realizando en adultos y no hay, a la fecha, estudios de tratamiento hechos específicamente en niños de tal forma que la aplicación de una terapia se hace en base a la extrapolación de data obtenida en adultos.

Dentro de las diferentes alternativas se in- 
cluyen antivirales como el Remdesivir, anticuerpos monoclonales para bloquear mediadores inflamatorios como el Tolicizumab, antiparasitarios como la Hidrocloroquina y la Ivermectina, el Suero de Pacientes Convalecientes con anticuerpos bloqueadores al virus, inmunomoduladores como el Interferón y las Gammaglobulinas Intravenosas, los corticoesteroides como la Dexametasona (con buenos resultados en pacientes severamente enfermos) y otros.

En la gran mayoría de niños el tratamiento es sintomático, usando paracetamol para la fiebre y malestar e hidratación. Solo en casos que progresen al MIS-C se usan gammaglobulinas intravenosas como parte del manejo.

\section{Prevención}

Como hemos visto, el SARS-CoV-2 es un virus altamente contagioso que se disemina rápidamente en la comunidad. La mejor forma de detener esta diseminación es evitando infectarse usando estrictas medidas de prevención.

Las tres medidas preventivas más efectivas hasta el momento son el uso de mascarillas en espacios públicos y reuniones para evitar eliminar e inhalar partículas contagiosas, el distanciamiento social de al menos 1,5 a 2 metros y el lavado y/o desinfección de manos frecuente que impide el contagio luego de tocar superficies contaminadas por el virus. Como hemos mencionado, los niños se contagian principalmente de los adultos que traen el virus a casa luego de adquirirlo en la comunidad; es por esto que desinfectarse antes de relacionarse con ellos es indispensable. Otra forma de contagio infantil es en reuniones con otros niños que pueden estar infectados. Por esto se deben evitar grupos de niños en parques, jardines, escuelas, etc.

Las medidas mencionadas se deben aplicar hasta que esté disponible una vacuna que sea eficaz y segura, que permita desarrollar anticuerpos bloqueadores contra el virus de manera duradera. Actualmente hay casi 200 vacunas siendo investigadas, algunas de las cuáles ya están en estudios clínicos de fase III que permitirán establecer su eficacia y seguridad con certeza antes de su uso en la población general.

\section{REVISIÓN BIBLIOGRÁFICA}

Berlin, D. A., Gulick, R. M.y Martinez, F. J. (2020). Severe COVID-19. N Eng J Med May 2020 doi: 10.1056/NEJMcp2009575

Cabeca, T., Granatto, C. y Bellei, N. (2013). Epidemiological and clinical features of human coronavisrus infection among diferente subsets of patients. Influenza Other Respir Viruses 2013 Nov; 7(6): 1040 - 1047

Cabero-Perez, M. J., Gomez-Acebo, I., Dierssen-Soto, G. y Llorca, J. (2020). Infección por SARS-CoV-2 en el embarazo y posibilidad de transmisión al neonato: una revisión sistemática. Semergen 46(S1): 47-54

Coronavirus Disease 19 (COVID-19). Available at: https://www.cdc.gov/coronavirus/2019ncov/covid-data/covidview/04102020/labsregions.html.

Dohchak, N., Singhal, T., Kabra, S. K. y Lodha, R. (2020). Pathophysiology of COVID-19: Why Children Fare Better Than Adults? Indian Journal of Pediatrics https://doi.org/10.1007/ s12098-020-03322-y

Ludvigsson, J. F. (2020). Systematic review of COVID-19 in children shows milder cases and a better prognosis than adults. Acta Paediatrica 2020; 00: 1-8

PAHO. (2020). Interpretation of laboratory results for COVID-19 diagnosis. PAHO/PHE/ IHM/COVID-19-20-0015 
Perez, G., Cordero, C. y Avendaño, L.F. (2020). Otro desafío de la naturaleza: El nuevo coronavirus virología y fisiopatología del SARSCoV-2. Neumología Pediatr 2020; 15 (2): 301307

Xia, W., Shao, J., Guo, Y., et al. (2020). Clinical and CT features in pediatric patients with COVID-19 infection: Different points from adults. Pediatric Pulmonology 2020; 1-6

Yonker, L. M., Neilan, A. M., Bartsch, Y., Patel, A. B., Regan, J., Arya, P., et al. (2020). Pediatric SARS-CoV-2: Clinical Presentation, Infectivity, and Immune Responses, The Journal of Pediatrics, doi: https://doi.org/10.1016/ j.jpeds.2020.08.037.
Zimmermann, P. y Curtis, N. (2020). Coronavirus infection in children including COVID 19 an overview of Epidemiology, Clinical Features, Diagnosis, Treatment and Prevention options in children. Pediatr Infectious Dis J. 39: 355368

Zunyou, W. y McGoogan, J. (2020). Characteristics and important lessons from the Coronavirus Disease 19 (COVID-19) outbreak in China, summary of reporto $f 2314$ cases from the chinese center for disease control and prevention. JAMA 323(13): 1239 - 1242 